\title{
Cigarette Consumption and Poverty Case Study: Poor Smoker Households in Bangka Belitung Islands
}

\author{
Agustina Neli ${ }^{*}$ and Usman Hardius \\ Politeknik Statistika STIS, Jakarta, Indonesia
}

\section{ARTICLE INFO}

Keywords:

Basic needs approach

Binary Logistic

Regression analysis

\begin{abstract}
Based on component of poverty line of Bangka Belitung Islands, percentage of cigarette consumption expenditures was the second largest for the poverty line, while rice as staple food only occupies the fourth position. Cigarettes do not contain calories, so they will not add calories by consuming them. It is possible for someone who has an expenditure above the poverty line to remain poor because many are spent for consuming cigarettes. The purpose of the study to analyze the impact of cigarette consumption on poverty status, with a simulation converting cigarette expenditure into spending on other foods containing calories. In particular, to study whether there is a change in poverty status after conversion of cigarette expenditure. And analyzing the influence of social, economic and demographic characteristics on changes in poverty status. The study focused on poor households that have cigarette expenditure. This study uses data of 7080 households from all regencies and cities in Bangka Belitung province, which collected from the field study by students of Polytechnic of Statistics STIS in 2017. The simulation results show that there is a significant change in poverty status when converting cigarette expenditure. And based on binary logistic regression analysis the results show that households with a higher level of education, status of head of household as employee or having a business, non-agricultural employment and an increase in per capita income have a greater tendency to change the poverty status of households. Thus, cigarette expenditure can change poverty status if it can be used for better needs.
\end{abstract}

\section{Introducton}

Poverty is still a problem that has not been resolved in all provinces in Indonesia. Various efforts have been made through government programs, including by improving the system to fulfill basic needs such as food, health services, sanitation counseling and other programs. Bangka Belitung is a province in Indonesia that has a relatively low poverty rate compared to other provinces in Indonesia. Figure 1 presents the percentage of poor people in the Bangka Belitung and Indonesia in 2007-2017. In general, the percentage of poor people in Indonesia and Bangka Belitung has decreased. In that period the percentage of poverty in the Bangka Belitung was always below the national poverty percentage, but it increased in 2013 to 2017. Statistics Indonesia, known in Indonesia as BPS measures poverty based on the concept of ability to meet basic needs (basic needs approach), the poor are defined as residents who have an average expenditure per capita per month below the poverty line. The poverty line is defined as the value of rupiah that must be spent by someone in a month in order to meet the basic needs of calorie intake of 2,100 kilo calories per capita per day, is known as food poverty line

* Corresponding Author E-Mail Address: neli@stis.ac.id 
plus the minimum non-food needs which are a person's basic needs and known as non-food poverty line.

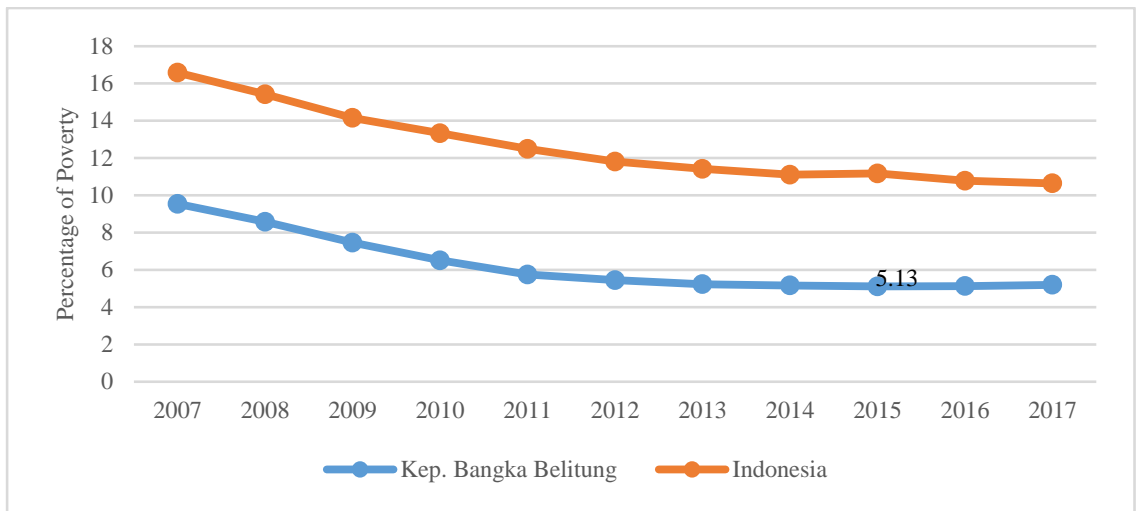

Figure 1. Percentage of poverty of Indonesia and Bangka Belitung in 2007-2017.

Based on the poverty line component of the Bangka Belitung in September 2016 (table 1), it can be seen that for urban areas the role of non-food commodities $(50.24 \%)$ is greater than food commodities (49.76\%), while for rural areas the role of commodities food $(56.1 \%)$ is still greater than non-food (43.9\%).The food commodities that most contributed were processed foods and beverages. Furthermore, cigarettes became the second largest contributor to the poverty line, $6.68 \%$ in urban and $7.84 \%$ rural areas. While rice ranks the fourth position for the poverty line.

Cigarettes do not contain calories (cigarette calories $=0$ ), so no matter how much expenditure to consume cigarettes, will not add calories to those who consume them. It is possible for someone who has expenses above the poverty line to remain poor because many are issued to consume cigarettes. If the household did not allocate one of its expenses for cigarette expenditure and diverted to other food expenditure that has a calorie value, the household could avoid the lack of basic needs or could even be saved to be used to meet future needs (Sari, 2017) .

Table 1.

Percentage of average expenditure per capita per month by commodity and regions, in Bangka Belitung Island in 2016

\begin{tabular}{llll}
\hline Commodity Type & Urban & Commodity Type & Rural \\
\hline Food & $\mathbf{4 9 , 7 6}$ & Food & $\mathbf{5 6 , 1}$ \\
Cigarette & $\mathbf{6 , 6 8}$ & Cigarette & $\mathbf{7 , 8 4}$ \\
Fish / shrimp / squid / scallops & 6,13 & Fish / shrimp / squid / scallops & 7,4 \\
Grains & 5,23 & Grains & 6,63 \\
Non Food & $\mathbf{5 0 , 2 4}$ & Non Food & $\mathbf{4 3 , 9}$ \\
Housing and household facilities & 27,6 & Housing and household facilities & 25,1 \\
Various goods and services & 10,46 & Various goods and services & 8,34 \\
Taxes, fees and insurance & 4,25 & Taxes, fees and insurance & 4,37 \\
Durable goods & 3,21 & Durable goods & 2,72 \\
Clothing, footwear and headgear & 2,87 & Clothing, footwear and headgear & 2,68 \\
The need for parties and ceremonies & 1,85 & The need for parties and ceremonies & 1,62 \\
Total & 100 & & 100 \\
\hline
\end{tabular}

Source: BPS of Bangka Belitung, 2016 
Spending on education and health sectors are an important investment for national development. The cost of education plays an important role in the sustainability of education. The higher level of education of human resources will affect to the level of the country's economy. With a higher level of education, will have better jobs and wages. Likewise with spending on health investment, health is the basis for work productivity and the capacity to study in school. Workers who are physically and mentally healthy will be more productive, and get high incomes (Atmawikarta, 2009). So, if household expenditure for cigarette consumption can be diverted to health and education expenditure, it will increase investment which will improve the welfare of the Indonesian people in general.

The research aims to determine the impact of cigarette expenditure on poverty status, by conducting a simulation of converting cigarette expenditure into other food expenditures that contain calories. Furthermore, it is seen whether there is a change in poverty status after the conversion of cigarette expenditure. In addition, this study also looks at the effect of social, economic and demographic characteristics on changing poverty status. The study specializes in the level of poor smokers' households, i.e. poor households that have cigarette expenditure.

\section{Study of Literature}

The calculation of poverty rates is done by using an approach to fulfill basic needs consisting of food and non-food needs arranged according to urban and rural areas taken based on the National Social and Economic Survey. Under this approach, poverty is seen as the inability of the economic side to meet the basic needs of food and non-food measured from the expenditure side, hereinafter referred to as the Poverty Line. The poor are residents who have an average expenditure per capita per month below the poverty line.

The consumption theory used is the Marshallian demand function theory. The Marshallian request function is obtained by reducing the utility function, by maximizing the utility that can be obtained and limited by a certain income (budget). Derivative is used to get extreme points (peak or maximum). Assuming consumers have a certain or constant income and spend all of their income (money income-held constant). Furthermore, maximizing consumer utilities with certain income, then these equations can be rearranged in a Lagrangian equation model, to get the consumer balance (consumer equilibrium), which is a condition where the will (indiference) equals or intersects with the ability (budget).

Smokers' households are households whose expenditure is spent on consumption of cigarettes. Household members are all people who usually reside in a household, both those who were at home at the time of enumeration or temporarily absent. Household members who have been traveling for 6 months or more, and household members who have traveled less than 6 months but intend to move / will leave the house, are not considered as household members. People who have lived in a household for 6 months or more or who have lived in a household for less than 6 months but intend to stay in that household are considered as household members. Per capita income is income earned by a household for a month divided by the number of household members.

Research on the relationship of poverty and cigarette consumption include research from Siahpush (2003) who conducted research on households in Australia. This study is related to the socioeconomic status of the pattern of cigarette consumption, the results show that households with low socioeconomic status will spend more income on cigarette expenditure. Hu, T-w, Mao, Z, Liu, Y, Beyer's, J de and Ong, M (2005) research in China, aims to look at differences in smoking behavior and cigarette expenditure among low and high income households. Variables used include food expenditure, home spending, clothing shopping and education spending. The results showed that households with low income expenditure on cigarettes are much lower than households with high income, especially for households in rural areas. However, if seen from the expenditure allocation to their income, poor households in 
China have a higher percentage of cigarette expenditure allocation compared to the percentage of cigarette expenditure allocation for non-poor households.

The result of Ulfah's research (2012) states that one of the factors that causes the high consumption of cigarettes is the inadequate knowledge capacity about the negative impact or danger of smoking to health. This is based on data on the growth rate of cigarette consumption from the elite to the bottom. There has been a decline in cigarette consumption in the elite community with adequate knowledge capacity. Conversely an increase in cigarette consumption patterns in the lower strata of society plus their low education. Suggestions conveyed in this study is the best way to be able to suppress the problem of smoking is to more aggressively provide counseling to the community, especially the middle to lower levels of society.

Firdaus and Suryaningsih (2010) research on cigarette consumption in poor households is associated with social demographic variables in Java. The results show the factors that influence to cigarette consumption in poor households are household income, the number of adult household members and the magnitude of non-smoking consumption of poor households. Research Chriswardani, et al (2012) said that the variable price of cigarettes, per capita expenditure, food expenditure, and age at the beginning of smoking influence the expenditure of cigarette consumption in poor households.

Triana (2011), her research results showed the factors that influence cigarette consumption in poor households are the number of household members, the type of residential area, and the education of head of household as control variables in the cigarette consumption model. Surjono and Handayani's research (2013) shows that smoking is a normal item for poor households, so that when there is an increase in income, cigarette consumption will increase. While the demand for cigarettes in poor households is inelastic, where when there is an increase in cigarette prices, the consumption of cigarettes in poor households decreases.

The results of correlation analysis in the research Sugiharti, et al (2015), showed that smoking behavior has a negative correlation with the health status of respondents. Individuals who smoke have a tendency to state that their health is generally not good. While the results of the probit regression analysis found that smoking behavior in Indonesia based on IFLS data for 2000 and 2007, is inversely proportional to the level of education, individuals with primary school equivalent (SD) have a greater tendency to smoke than individuals with higher education levels. Associated with the level of income and status of home ownership shows that smoking behavior in Indonesia is related to low and middle income population.

Djibuti, et al (2007), analyze social, economic and demographic factors that influence household expenditure on cigarettes in Azerbaijan, Georgia, Kazakhstan, Kyrgyzstan, Russian Federation, and Tajikistan. The results showed that there were significant differences found between the average expenditure on cigarettes between rich and poor households. In absolute terms, the rich spend far more than the poor. Poor households allocate a higher portion of their monthly consumption for cigarette products. There is a negative relationship between the level of tertiary education and expenditure on cigarette consumption. And there is a positive relationship between household spending on cigarettes with alcohol consumption.

Bazotti's research (2015) aims to explain the characteristics of the Brazilian population who spend their money on cigarettes, using data from IBGE in 2008-2009. The results of the study 10 percent of the Brazilian population spends money on cigarettes. These smokers have an older age, low income, and low education compared to nonsmokers, as well as most men. For this population of smokers, 1.5 percent of their income is used for cigarette consumption. The expenditure of cigarettes in a household will be more useful if it is used to meet more important household needs.

Perera (2017), conducted research in Monaragala, a rural agricultural area in Sri Lanka. Using cross section data, the research aims to explain the expenditure of cigarettes and their 
relationship with food expenditure and education expenditure at the household level. The results showed the poorest households had the highest allocation of expenditure for cigarettes. And household expenditure for tobacco is negatively related to education expenditure. In addition, research by Beyer, Joy de, C. Lovelace and A. Yurekli shows that the implications of tobacco prevalence are high among men with low education and low income, which increases their relative risk of serious illness and early death. Policies and interventions to help smokers quit, and to prevent others from starting, are an important part of national and international efforts to improve the health and welfare of the poor.

It can be concluded from previous studies that cigarette consumption is one of the causes of poverty, and there are differences in the social, economic and demographic characteristics of poor households against cigarette consumption patterns. Therefore, this study aims to look at the impact of cigarette expenditure on poverty by converting cigarette expenditure to other food expenditures containing calories, as well as looking at the effect of social, economic and demographic characteristics on changing poverty status in poor smokers in the Bangka Belitung Islands in in 2017.

\section{Hypotheses}

Based on the explanation of the study literature and previous studies, hypotheses of this research are:

Hypothesis 1: Cigarette expenditure is the cause of many households becoming poor.

Hypothesis 2: Many households can actually avoid poverty if spending on smoking is diverted for consumption that has a caloric value.

Hypothesis 3: Social, economic and demographic characteristics have an influence on changes in the poverty status of poor smokers households

\section{Methodology}

The study uses a sample unit of poor households that have cigarette consumption expenditure. The selection of the sample units of poor households uses the poverty line in 2017 for each district/city in the Bangka Belitung Islands. The data used in the study are data on the results of street vendors of Polytechnic Statistics STIS students in Bangka Belitung Islands in 2017. The total sample were 7080 households, were interviewed with a questionnaire on Computer Assisted Personal Interviewing (CAPI).

Poverty status is measured based on the ability of households to meet the needs of at least 2100 kcalories per capita per day. Changes in poverty status can be seen from changes in the results of the conversion of food expenditure without cigarettes with the results of food expenditure conversion plus cigarette expenditure. If after entering the expenditure of calorie conversion and the results are more than 2100 calories, then the household is categorized as successful in changing its poverty status, conversely if the calorie conversion result is still below 2100 calories, the household fails to change its poverty status. How to convert the amount of food expenditure into the form of calorie needs, can be calculated based on the following formula:

$$
\begin{aligned}
\text { Calorie requirements } / \text { capita }= & (\text { Food Expenditure per capita * 2100 }) / \text { Food Poverty } \\
& \text { Line of Bangka Belitung } \\
\text { Calorie requirements } / \text { capita }= & (\text { Food }+ \text { cigarettes Expenditure per capita * 2100 }) / \\
& \text { Food Poverty Line of Bangka Belitung }
\end{aligned}
$$

\subsection{Logistic Regression Analysis}

Binary logistic regression analysis is used to determine the effect of social, economic and demographic characteristics on changes in poverty status. Demographic characteristics of poor households will be seen from the household's age variable, the number of household members. The characteristics of results are assessed in terms of the level of education of the household 
head, the work field of the household head and the status of the work household head. While the economic characteristics in terms of income per capita in a month, spending on health and spending on education. Logistic regression is an approach to making prediction models, with dichotomous scale dependent variables, namely nominal data scales with two categories, for example: Yes and No, Good and Bad or High and Low.

Logistic regression applies the maximum likelihood estimation (MLE) method in generating estimation values after transforming independent variables into a logit variable. Logistic regression estimates the probability of a particular event to occur. The logistic regression probablilita model meets the following formula:

$$
E(Y \mid x)=\pi(x)=\frac{\exp \left(\beta_{0}+\beta_{1} x_{1}+\ldots+\beta_{p} x_{p}\right)}{1+\exp \left(\beta_{0}+\beta_{1} x_{1}+\ldots+\beta_{p} x_{p}\right)}
$$

\subsection{Specification Research Model}

The form of the logistic regression model used in the study is as follows:

$$
\begin{aligned}
\ln \left(\frac{p}{1-p}\right)= & \beta_{0}+\beta_{1} \text { Edu } 1+ \\
& \beta_{2} \text { Edu } 2+\beta_{3} \text { LapUs } 1+\beta_{4} \text { LapUs } 2+\beta_{5} \text { Status } 1+\beta_{6} \text { Status } 2+ \\
& +\beta_{7} \text { SumART }+\beta_{8} \text { AgeKRT }+\beta_{9} \text { ExpHealth }+\beta_{10} \text { ExpEdu }+\beta_{11} \text { Incap }
\end{aligned}
$$

Where,

$p=$ Chance of household success to change poverty status

$E d u l=$ Secondary education

$E d u 2=$ Higher education

LapUs1 = Employment of head of household in Mining and quarrying sector

LapUs2 = Employment of head of household in other sectors (besides agriculture and mining)

Status $1=$ Head of household 's employment status as a worker / laborer

Status2 $=$ The work status of the head household has a business

SumART $=$ Number of household members

AgeKRT $=$ Age of head of household

ExpHealth = Expenditure of householed for health

$\operatorname{ExpEdu}=$ Expenditure on householed for education

Incap $=$ Income per capita

$\beta i=$ Coefficient value of each independent variable,

$i=0,1,2, \ldots 11$.

\section{Results}

Household poverty is measured by the ability to meet the needs of at least 2100 kcalories per capita per day. Based on Figure 2, there are 5.85 percent of poor households, where if viewed from the presence or absence of cigarette expenditure in these households, it can be seen that poor households who smoke (have cigarette expenditure) amounted to 52.22 percent. In this case it can be said that poor households are mostly smokers.

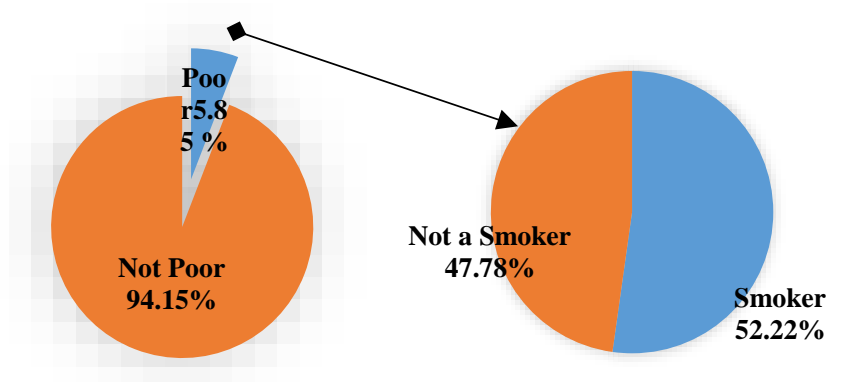

Figure 2. Percentage of households based on poverty status and smoking household in the Bangka Belitung Islands, 2017. 
Cigarette expenditure has a major contribution in determining the poverty line, even though cigarettes themselves do not have a calorie contribution (cigarette calories $=0$ ). On average, the expenditure of poor households for their own cigarette needs is quite large, around 19.75 percent of their total food expenditure. If cigarette expenditure is diverted to food expenditure containing calories, by converting it to the calorie needs per capita per day (2100 kcalories), then it can be seen how the poverty status of smokers poor households changes.

If cigarette expenditure is diverted for food needs that can add calories, then there are 32.43 percent of smokers poor households that can change their poverty status, from poor to nonpoor households. While 67.57 percent do not experience changes in poverty status after diverting their cigarette expenditure for calorie food needs, as can be seen in Figure 3. In this case it can be said that there are poor households in vulnerable vulnerable positions, where if they can divert the expenditure of cigarettes to expenditures that are more useful then it can change its poverty status. While most of them are acute poor households, even though their cigarette expenditure is diverted to more useful needs, they are still in the status of poor households.

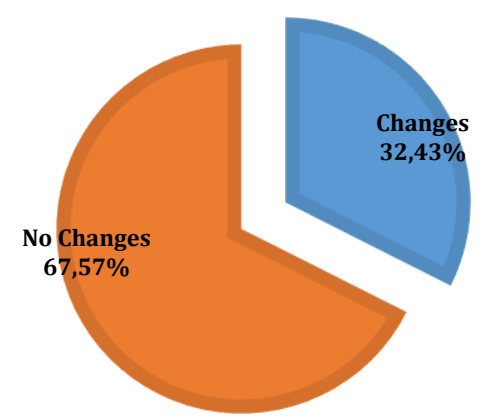

Figure 3. Percentage of change in poverty status of poor smokers households.

Some poor households work in the agricultural sector. Figure 4 shows that in terms of employment types, 45 percent of households in the mining and exclusion sector can change their poverty status, and 40 percent of households with other sectors can change poverty status. While for households in the agricultural sector the lowest can change their poverty status, only 33 percent. This is in line with the results of several previous studies which showed that the agricultural sector is the biggest contributor to poverty.

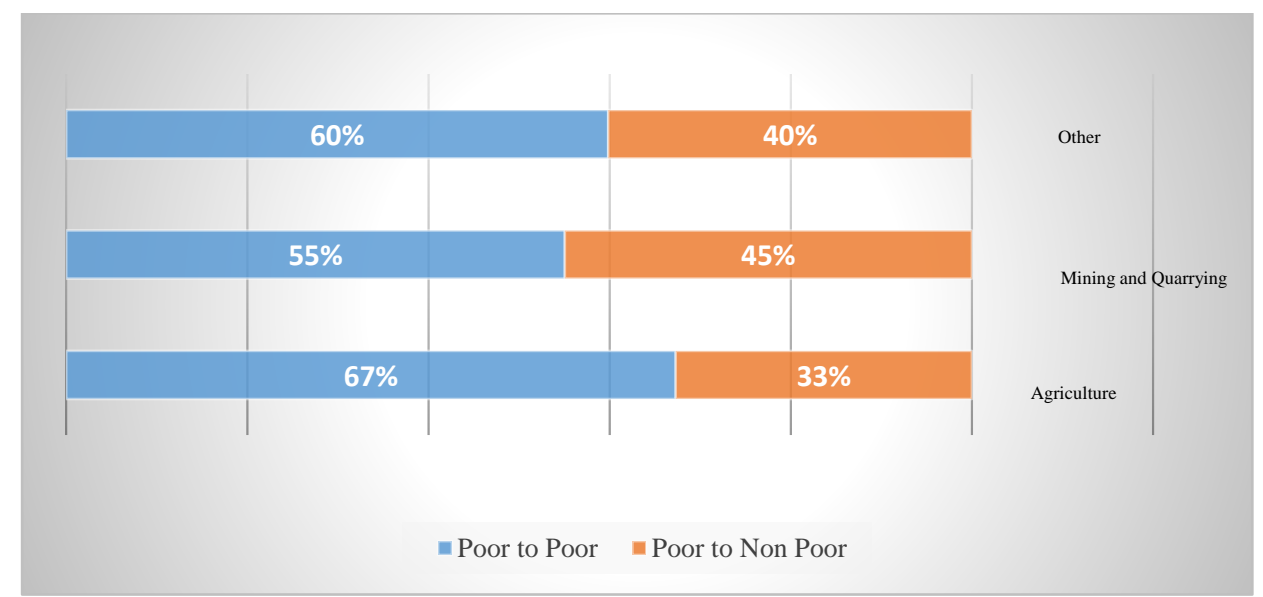

Figure 4. Percentage of change in household poverty status by employment sector. 


\subsection{The Effect of Social, Economic and Demographic Characteristics on Changes in the Poor Poverty Status}

The results of model match test based on the Hosmer \& Lemeshow goodness of fit Test table with a test statistic is 6.197 and a p-value is 0.625 , then at a significance level 0.05 the model can be said to be fit, which means there is no difference between observation and prediction results from the model. Also based on the value of the hit ratio (overall percentage) 67 percent, meaning that the model can classify objects correctly by 67 percent.

Based on the statistical value of the test $G=-2 \ln$ likelihood $(2320,789)$ or can be seen from the p-value of the model in the omnibus table test of model coefficient, showing the p-value $<0.05$. It means that there is at least one independent variable that has a statistically significant effect on the chance of poverty change status. The result of partial test using Wald test statistics that follow the chi-square distribution with free degrees 1 . Or can be seen from the significance value. Based on the variables in the Equation table, the estimated coefficient of regression results can be seen in table 2 .

Table 2.

Estimated Regression Coefficient

\begin{tabular}{lccccc}
\hline Variabel & B & Wald & df & Sig & Exp (B) \\
\hline Sum_ART &,- 390 & 80,316 & 1 &, 000 &, 677 \\
Age_KRT &, 009 & 3,670 & 1 &, 055 & 1,009 \\
Edu & & 6,920 & 2 &, 031 & \\
Edu1 &, 235 & 4,575 & 1 &, 032 & 1,264 \\
Edu2 &, 529 & 4,029 & 1 &, 045 & 1,697 \\
LapUs & & 9,288 & 2 &, 010 & \\
LapUs1 &,- 431 & 9,219 & 1 &, 002 &, 650 \\
LapUs 2 &,- 314 & 4,656 & 1 &, 031 &, 731 \\
Status & & 8,231 & 2 &, 016 & \\
Status1 &, 198 & 1,556 & 1 &, 212 & 1,218 \\
Status2 &, 417 & 7,206 & 1 &, 007 & 1,517 \\
ExpHealth &, 007 &, 062 & 1 &, 804 & 1,007 \\
ExpEdu &, 005 &, 098 & 1 &, 755 & 1,005 \\
InCap &, 276 & 28,815 & 1 &, 000 & 1,318 \\
Constant &, 312 & 1,089 & 1 &, 297 & 1,366 \\
\hline
\end{tabular}

The results of the estimated binary logistic regression analysis obtained the logit equation as follows:

$$
\begin{aligned}
& \ln \left(\frac{p}{1-p}\right)=0,312+0,235 \text { Edu } 1^{*}+0,529 \text { Edu }^{*}-0,431 \text { LapUs }^{*}-0,314 \text { LapUs }^{*}+ \\
& 0,198 \text { Status } 1+0,417 \text { Status } 2^{*}-0,390 \text { Sum }_{A R T}{ }^{*}+0,009 \text { Age }_{K R T}{ }^{* *}+ \\
& 0,007 \text { ExpHealth }+0,005 \text { ExpEdu }+0,27 \text { InCap }
\end{aligned}
$$

Based on the model can be interpreted as follows:

If education of head of household reaches secondary education, then poor households have a tendency to change poverty status from poor to non-poor by 1,264 times compared to households with low education, assuming the other variables are the same. Likewise, if education of head of household reaches top education, poor households have a tendency to change poverty status from poor to non-poor by 1,697 times compared to low education, assuming the other variables are the same. This shows that poor households with higher education of head of household have a higher chance of changing their poverty status compared to poor households with lower education.

If the employment sector of the head of household is agriculture, then the household has a tendency to change its poverty status from poor to non-poor 0.650 times compared to 
households with head of household who's worked in sector mining and quarrying, assuming the other variables are the same. Likewise with other employment sectors (other than agriculture, mining and quarrying), these households have a tendency to change their poverty status 0.731 times compared to households with head of household whose worked in sector mining and quarrying. In other words, the opportunity for households with mining and excavation employment sector is greater to be able to change their poverty status compared to households with agriculture and other KRT employment sectors.

If status of the head of household work as labor or employee, then poor households have a tendency to change their poverty status from poor to non-poor by 1,517 times compared to households with a household head whose work status is free, assuming the other variables are the same. This means that the opportunity for households with employment status as workers or employees to change poverty status is greater than households with head of household work status of free workers.

If the number of household members increases by 1-person, poor households have a tendency to change poverty status by 0.677 assuming the other variables are the same. The opportunity for households with a greater number of ART to change their poverty status is smaller than households with a lower number of ART.

If there is an increase in income per capita of 1 million rupiah, then smoker's poor households have a tendency to change poverty status by 1,138 times assuming the other variables are the same. This means that poor households that can increase their per capita income have greater opportunities to be able to change poverty status.

If there is an increase in health expenditure of 1 million rupiah, then poor smokers households have a tendency to change poverty status by 1,007 times assuming the other variables are the same. If there is an increase in education expenditure of 1 million rupiah, then poor smokers households have a tendency to change poverty status by 1,005 times assuming the other variables are the same. If the household head's age increases by 1 year, then poor smokers have a tendency to change poverty status by 1,009 times, assuming the other variables are the same. The opportunity for households with older household heads can change their poverty status more than households with younger household heads. If the household head status has a business, poor households have a tendency to change their poverty status from poor to nonpoor by 1,218 times compared to households with a household head whose employment status is free, assuming the other variables are the same. This means that the opportunity for households with status the head of household have a business to be able to change poverty status is greater than his work status as free workers. But in this study these variables are not significant at the 5 percent significance level.

\section{Discussion and Conclusion}

Based on the results of the analysis shows that poor households in Bangka Belitung Islands are mostly smokers. They allocated their expenditure for consumption cigarettes quite large compared to other food expenditures. Furthermore, cigarettes became the second largest contributor to the poverty line in Bangka Belitung island.

The simulation results by converting cigarette expenditure into food expenditure containing calories, some households can change their poverty status from poor to non-poor household. So education about the dangers of smoking for health needs to be increased. The government also has a role to play in reducing cigarette consumption, by limiting production and increasing cigarette taxes. However, most households do not change their status. In this case a household that cannot change its poverty status can be said to be an acute poor household. They need special attention from the government, because they cannot escape poverty by themselves.

The changes in the poverty status of a smoker household are influenced by the economic, social and demographic characteristics of the household. Household with headhousehold who have 
permanent jobs, work in the mining and quarrying sector, and have an increase in family income are more likely to change their poverty status. The higher education of head of household, is expected to provide a good influence for his family to better understand the dangers of smoking. In addition, families with fewer members have a greater chance of changing their status. In this case, it shows that home financing is less and can improve household welfare. The status of the head household as a worker / employee has a tendency to change the status of greater poverty. An increase in per capita income can change poverty status. Poor households with a greater number have less chance of changing poverty status. An increase in per capita income can change poverty status. Poor households with a greater number of household member .

\section{Reference}

Atmawikarta, A. 2009. Health Investment for Economic Development. http://www.bappenas.go.id/files/1513/5027/.../arum_20091015100705_2301_o.doc

Bazotti, et al. 2014. Smoking and poverty in Brazil: an analysis of the profile of the smoking population based on the 2008-09 Brazilian government Family Budget Survey

Official News of Statistics of the Bangka Belitung Islands. No.05/01/ 19/ Th.XIV, 24 October 2016

Beyer, Joy de, C. Lovelace and A. Yurekli., 2001. Poverty and Tobacco.

Chriswardani, et al. 2012. Consumption of Poor Household Cigarettes in Indonesia and the Formulation of Policy Agenda Consumption of Poor Household Cigarettes in Indonesia and the Formulation of Policy Agenda Vol. 1 No. 2: hal. 69-76.

Djibuti, et al. 2007. Influence of household demographic and socio-economic factors on household expenditure on tobacco in six New Independent States. BMC Public Health. http://biomedcentral.com/1471-2458/7/222

Firdaus dan Suryaningsih (2010). 2010. Poverty and High Cigarette Consumption: Factors That Cause Difficult Implementation of Green Economy in Java. http://fem.ipb.ac.id/b/orange book-green economy

$\mathrm{Hu}$, et al. 2005. Smoking, Standard of Living, and Poverty in China. Tobacco Control, Vol.4, No. 4, pp 247-250. Downloaded from http://tobaccocontrol.bmj.com/

Perera K. Manuju et al. 2017. Household Expenditure on Tobacco Consumption in a PovertyStricken Rural District in Sri Lanka. Asia Pacific Journal of Public Health.

Sari Haifa, 2017. Factors affecting expenditure on cigarette consumption in poor households in Aceh Province. Journal of Darussalam Economic Perspective. Volume 3 Nomor 2, September 2017

Setiawan and Wahyuni. The Random Effect Approach for Panel Data on Cigarette Consumption Study in Indonesia 2007 - 2012. 2015. Proceedings of the National Seminar on Mathematics and Mathematics Education. ISSN 978-602-73403-0-5. http://eprints.uny.ac.id/id/eprint/29678

Siahpush, M. 2003. Socioeconomic Status and Tobacco Expenditure among Australian Households: Results from the 1998-99 Household Expenditure Survey. Journal of Epedemiology and Community Health, Vol. 57, No. 10, hal. 798-801.

Siahpush M, Borland R, Scollo M. 2003. Smoking and financial stress. Tobacco Control 2003;12:60-6. 
Sugiharti and Sukartini. 2015. Cigarette Consumption Based on Individual Characteristics in Indonesia. Journal of Quantitative Applied Economics. Vol. 8 no 1. February 2015. http://www.cdc.gov/tobacco/data_statistics/fact_sheets/fast_fs/

Sujono and handayani. 2013. Impact of Cigarette Revenue and Prices on Cigarette Consumption Rates in Poor Households in Indonesia. BPPK Journal, Vol 6 Nomor 2, 2013, Page 19-34

Triana, R.A. Leisa. 2011. Effect of Poor Rice Subsidy Policy and Direct Cash Assistance on Telecommunications Expenditure of Poor Household Cigarettes in Java. Thesis. Postgraduate of Bogor Agricultural University, Bogor.

Ulfah, Rafiqah. 2012. Development of Cigarette Consumption among Low Economic Communities.

http://kesehatan.kompasiana.com/medis/2012/03/18/perkembangan_konsumsi_rokok_dika lanan_masyarakat_ekonomi

Wee Shu-Hui. Analyzing the Expenditure Share of Smoking in China. University of California, Berkeley. Tesis. 